\title{
Prognostication in palliative care
}

\author{
Authors: Christina Chu, ${ }^{A}$ Nicola White ${ }^{B}$ and Patrick Stone ${ }^{C}$
}

An accurate prognosis about how long a terminally ill patient has left to live, when disclosed sensitively in open discussions, can facilitate patient-centred care and shared decision making. In addition, several guidelines, policies and funding streams rely, to some extent, on a clinician estimated prognosis. However, clinician predictions alone have been shown to be unreliable and over-optimistic. The factors underlying clinicians' prognostic decisions (particularly at the very end of life) are beginning to be elucidated. As an alternative to clinicians' subjective estimates, a number of prognostic algorithms and scores have been developed and validated, but only a few have consistently shown superiority to clinician predictions. Therefore, an element of uncertainty remains and this needs to be acknowledged when having conversations with patients and their families. Guidelines are available to advise clinicians about how to prepare for, participate in and record prognostic conversations.

\section{Importance of prognostication}

Being able to provide an accurate prognosis for survival is important for patients, carers and clinicians. For patients, it allows time to prepare for approaching death, for example, by making financial plans or saying goodbye. For clinicians, an awareness and consideration of prognosis may be important for informing decision making surrounding medical interventions, achieving preferred place of care and advance care planning. Open discussion about prognosis can facilitate patient-centred care and shared decision making. ${ }^{1}$

The recently published NHS Long Term Plan acknowledges that, for an ageing society with multiple long-term conditions and increasing complexity, it is important to identify patients in the last year of life with the aim of achieving proactive and personalised care plans. ${ }^{2}$ Table 1 summarises how current guidance, policies and funding streams for patients rely, to some extent, on estimated prognoses.

Authors: A academic clinical fellow, University College London, London, UK and specialty trainee in palliative medicine, Barts Health NHS Trust, London, UK; ${ }^{B}$ research associate, Marie Curie Palliative Care Research Department, University College London, London, UK; ' head of Marie Curie Palliative Care Research Department, University College London, London, UK

\section{Predictions of less than 1 year}

The surprise question was developed to identify patients who may benefit from a palliative approach to future care or who may need referral to specialist palliative care. To use the surprise question, clinicians should ask themselves, 'Would I be surprised if this patient were to die in the next 6-12 months?' It is used in routine clinical practice in a variety of settings and forms part of the Gold Standards Framework (GSF) proactive identification guidance (PIG), which is supported by NICE guidance., ${ }^{3,8}$ In GSF PIG, the surprise question is intended to be considered in combination with other (general and disease-specific) prognostic factors.

A systematic review found the accuracy of the surprise questions is variable; there is a wide range of sensitivity (the ability to recognise patients who are dying; 11.6 to $95.6 \%$ ), specificity (the ability to recognise patients who are not dying; 13.8 to $98.2 \%$ ) and positive predictive value (the proportion of patients who die when the clinician predicts that they will die; 13.9 to $78.6 \%$ ). ${ }^{9}$ The negative predictive value (the proportion of patients who survive when clinicians predict that they will

\section{Key points}

Prognostic information is frequently helpful for patients, their carers, and for healthcare professionals.

Understanding patients' prognoses can facilitate access to certain services and benefits.

Clinical predictions of survival are widely used and are helpful for identifying patients at different stages of their disease trajectory. Clinicians should be aware of the risk of overestimation, especially in temporal estimates.

Prognostic scores may provide more objective and/or more accurate prognoses than clinician predictions alone.

Whichever method for formulating a prognosis is used, it is important that information is communicated sensitively and with an appropriate degree of uncertainty.

KEYWORDS: Palliative care, terminal care, prognosis, communication, algorithm 
Table 1. Examples of situations that utilise

estimated length of survival

\begin{tabular}{|c|c|}
\hline $\begin{array}{l}\text { Estimated } \\
\text { length of } \\
\text { survival }\end{array}$ & Relevance \\
\hline \multirow[t]{2}{*}{$\begin{array}{l}\text { Less than } \\
1 \text { year }\end{array}$} & $\begin{array}{l}\text { The approximate prognosis of patients to whom } \\
\text { 'end of life' care policy documents and guidelines } \\
\text { relate, for example National Institute for Health } \\
\text { and Care Excellence and General Medical Council } \\
\text { guidance. }\end{array}$ \\
\hline & $\begin{array}{l}\text { One of the factors that helps to determine the } \\
\text { suitability of patients for inclusion on community } \\
\text { end of life care registers (eg the Gold Standards } \\
\text { Framework). }\end{array}$ \\
\hline $\begin{array}{l}\text { Less than } \\
6 \text { months }\end{array}$ & $\begin{array}{l}\text { The prognosis required for completion of a } \\
\text { DS1500 form which allows patients access } \\
\text { to certain welfare benefits (eg Personal } \\
\text { Independence Payment, Universal Credit or } \\
\text { Attendance Allowance) under the 'special rules'. }\end{array}$ \\
\hline $\begin{array}{l}\text { Weeks to } \\
\text { months }\end{array}$ & $\begin{array}{l}\text { Clinicians completing the NHS fast-track tool for } \\
\text { continuing care funding are advised that suitable } \\
\text { patients should have a 'rapidly deteriorating } \\
\text { condition and may be entering a terminal phase'. } \\
\text { Furthermore, applications should be 'supported } \\
\text { by a prognosis... [but] strict time limits that base } \\
\text { eligibility on a specified expected length of life } \\
\text { remaining should not be imposed'. } 5 \text { Nonetheless, in } \\
\text { the authors' experience applications for fast-track } \\
\text { NHS continuing care funding are most likely to be } \\
\text { approved if the prognosis is weeks to a few months. }\end{array}$ \\
\hline $\begin{array}{l}\text { Less than } \\
2 \text { weeks }\end{array}$ & $\begin{array}{l}\text { Most hospices offer inpatient admission either } \\
\text { for symptom control or terminal care. Although } \\
\text { no specific prognosis is mandated for terminal } \\
\text { care admissions most hospices operate a 'rule } \\
\text { of thumb' whereby terminal care admissions } \\
\text { are targeted at those with a prognosis of less } \\
\text { than } 2 \text { weeks. The average length of stay for } \\
\text { admissions at inpatient hospices is } 15 \text { days. }\end{array}$ \\
\hline $\begin{array}{l}\text { Less than } \\
72 \text { hours }\end{array}$ & $\begin{array}{l}\text { The approximate prognosis of patients who } \\
\text { would be deemed appropriate to be managed } \\
\text { using an end of life care plan. Specific National } \\
\text { Institute for Health and Care Excellence guidance } \\
\text { is also available for patient care in the last days } \\
\text { of life if there are no local care plans available. }\end{array}$ \\
\hline
\end{tabular}

survive) has a narrower range at 61.3 to $99 \%$. The accuracy did not significantly change when the question was altered to refer to different timeframes (eg 'Would you be surprised if the patient died in the next 30 days?').

\section{Predictions of weeks to months}

Clinical predictions of survival come in many forms. Clinicians may state that they expect a patient to live for a specific period of time such as 5 days, 3 weeks or 4 months. These are known as continuous temporal predictions. Alternatively, clinicians may provide a survival estimate in discrete categories such as 0 to
2 days, 3 to 7 days, or greater than 7 days. These are known as categorical temporal predictions. Finally, clinicians may frame their predictions in terms of probabilities, such as the likelihood a patient will die in the next week or the next month. These are known as probabilistic estimates of survival.

Clinicians' temporal predictions (either categorical or temporal) are frequently inaccurate and unreliable, with a systematic tendency to over-estimate. ${ }^{10,11}$ Although individual studies have suggested that accuracy may depend on experience, specialty or level of acquaintance with the patient, there is no consistent evidence that a particular group or sub-group of clinicians are more accurate than others. There is a suggestion that probabilistic predictions may be more accurate than temporal estimates, but fewer studies use this method. ${ }^{12}$

There is some evidence the accuracy and consistency of survival predictions can be improved by using algorithms and/ or prognostic scoring systems. Table 2 provides examples of prognostic tools that have been validated in palliative care settings (hospital, hospice and community). ${ }^{13}$ Most of these tools have been developed predominantly (or exclusively) in advanced cancer populations. Therefore, clinicians caring for patients with advanced organ failures, degenerative neurological conditions and frailty should use these tools with caution.

A limitation of some prognostic tools is that they rely, to a greater or lesser extent, on the clinicians' own prediction of survival. This can be a drawback for clinicians who wish to use a prognostic tool to provide an 'objective' estimate uncontaminated by their own subjective judgement. Some prognostic tools incorporate blood test results and although this can improve prognostic accuracy it can reduce their practical usefulness in palliative care practice where the philosophy is generally to minimise unnecessary procedures. Finally, although clinician predictions are known to be inaccurate, very few existing prognostic tools have consistently been shown to provide a superior performance.

\section{Predictions of imminent death ( $<72$ hours)}

A phenomenon known as the 'horizon effect' suggests it is easier to predict events expected to happen imminently in contrast to those further in the future. For example, a weather prediction 3 days in advance is likely to be more accurate than one of 14 days. By the same logic it ought to be easier to predict when death is imminent than when death is still a few weeks or months away. Very few studies have systematically addressed this question. However, a systematic review found some evidence to support this hypothesis. ${ }^{10}$

Several studies have tried to understand factors that may predict imminent death. A range of methods have been used in this pursuit: by identifying signs and symptoms that forecast the last 72 hours of life, by asking clinicians what information they use to predict the last days of life and by studying subconscious clinical decision-making processes.

Patients with palliative performance scale (PPS) levels of $10 \%$, $20 \%$, and $30 \%$ (ie bed bound, needing all care, reduced oral intake and drowsy) have a median survival of 2, 4 and 13 days, respectively, thus probably making the PPS the most suitable prognostic tool for identifying patients at risk of imminent death. ${ }^{14}$

Prospective studies have monitored clinical signs in advanced cancer patients approaching death and found 13 indicators with high sensitivity ( $>95 \%$ ) and positive likelihood ratios $(>5)$ in the last 72 hours of life. ${ }^{15}$ These signs were pulselessness of radial 
Table 2. Examples of prognostic tools validated in palliative care settings

\begin{tabular}{|c|c|c|c|c|}
\hline Prognostic tool & Validated populations & Type of prediction & Factors included in score & Comments \\
\hline $\begin{array}{l}\text { Palliative Prognostic } \\
\text { Score (PaP) }\end{array}$ & $\begin{array}{l}\text { Mixed advanced } \\
\text { disease: cancer and } \\
\text { non-cancer }\end{array}$ & $\begin{array}{l}\text { Probability of surviving } \\
30 \text { days - score assigns } \\
\text { patients to one of three } \\
\text { groups with }<30 \% \text {, } \\
30-70 \% \text { or }>70 \% \\
\text { probability of survival }\end{array}$ & $\begin{array}{l}\text { Symptoms of dyspnoea and } \\
\text { anorexia } \\
\text { Functional status } \\
\text { Clinician predicted survival } \\
\text { Laboratory results: white cell } \\
\text { count and lymphocyte \% }\end{array}$ & $\begin{array}{l}\text { A hybrid assessment } \\
\text { method which combines } \\
\text { clinicians' survival } \\
\text { estimates with clinical } \\
\text { features and blood results }\end{array}$ \\
\hline $\begin{array}{l}\text { Palliative } \\
\text { Performance Scale } \\
\text { (PPS) }\end{array}$ & $\begin{array}{l}\text { Mixed advanced } \\
\text { disease: cancer and } \\
\text { non-cancer }\end{array}$ & $\begin{array}{l}\text { Each decreasing PPS } \\
\text { level (deciles from } 100 \\
\text { to } 0 \% \text { ) is associated } \\
\text { with a shorter survival; a } \\
\text { study has derived median } \\
\text { survival in days for PPS } \\
\text { levels } 10-70 \%\end{array}$ & $\begin{array}{l}\text { Functional status based on } \\
\text { ambulation activity and } \\
\text { evidence of disease self- } \\
\text { care intake (food and fluid) } \\
\text { conscious level }\end{array}$ & $\begin{array}{l}\text { Does not rely on blood } \\
\text { results or clinician } \\
\text { predictions of survival. Not } \\
\text { specifically developed as a } \\
\text { prognostic tool and may } \\
\text { therefore be missing some } \\
\text { key prognostic variables. }\end{array}$ \\
\hline $\begin{array}{l}\text { Prognosis in } \\
\text { Palliative care study } \\
\text { (PiPS-A) score }\end{array}$ & $\begin{array}{l}\text { Advanced incurable } \\
\text { cancer }\end{array}$ & $\begin{array}{l}\text { Provides a probability } \\
\text { of surviving days ( } 0-14 \\
\text { days), weeks ( } 15-56 \text { days) } \\
\text { or months ( }>56 \text { days) }\end{array}$ & $\begin{array}{l}\text { Clinical information on } \\
\text { diagnosis } \\
\text { Sites of metastases } \\
\text { Presence or absence of key } \\
\text { symptoms } \\
\text { Cognitive status } \\
\text { Functional status }\end{array}$ & $\begin{array}{l}\text { Does not rely on blood } \\
\text { results or clinician } \\
\text { predictions of survival }\end{array}$ \\
\hline $\begin{array}{l}\text { Prognosis in } \\
\text { Palliative care study } \\
\text { (PiPS-B) score }\end{array}$ & & & $\begin{array}{l}\text { Similar factors as for PiPS-A } \\
\text { but with addition of blood } \\
\text { results }\end{array}$ & $\begin{array}{l}\text { Does not rely on clinician } \\
\text { predictions of survival. In } \\
\text { one study was found to be } \\
\text { better than a doctor's or a } \\
\text { nurse's survival prediction }\end{array}$ \\
\hline $\begin{array}{l}\text { Palliative Prognostic } \\
\text { Index (PPI) }\end{array}$ & $\begin{array}{l}\text { Advanced incurable } \\
\text { cancer }\end{array}$ & $\begin{array}{l}\text { Probability of surviving }<3 \\
\text { weeks or }<6 \text { weeks }\end{array}$ & $\begin{array}{l}\text { Performance score } \\
\text { Oral intake } \\
\text { Clinical signs of oedema and } \\
\text { delirium } \\
\text { Symptoms of dyspnoea }\end{array}$ & $\begin{array}{l}\text { Does not rely on blood } \\
\text { results or clinician } \\
\text { predictions of survival }\end{array}$ \\
\hline
\end{tabular}

artery, respiration with mandibular movement, urine output $<100 \mathrm{ml} / 12$ hours, Cheyne-Stokes breathing, audible airway secretions, non-reactive pupils, decreased response to verbal or visual stimuli, inability to close eyelids, drooping of nasolabial fold, hyperextension of neck, grunting of vocal cords and upper gastrointestinal bleed. This is an area of on-going research and caution must be exercised when interpreting results until they have been replicated. Some of the purported signs may be difficult to spot and the sensitivity of some were quite low, which means their absence does not exclude the possibility of imminent death. Moreover, it is unclear whether rigorous assessment of these clinical features would be any more accurate than relying on clinicians' predictions.

Using a Delphi survey of international palliative care experts the factors used in conscious decision making were explored. There was over $50 \%$ consensus that pattern of breathing, level of consciousness and cognition, emotional state, general deterioration, intake of fluid and food, and skin changes are clinical aspects most commonly used to predict the last hours and days of life. ${ }^{16}$

Understanding intuition in predicting imminent death is a difficult area to study. Clinicians themselves are often unable to articulate the subconscious thought processes underlying their decisions, often referring to it as a 'sixth sense'. A recent study used judgement analysis to try to understand doctors' prognostic decision-making processes. From an original group of 99 palliative care doctors, the best 14 prognosticators were identified. Their subconscious decision-making strategies were probed by determining how their judgments altered in certain experimental conditions. The PPS was the most influential factor, followed by the presence of Cheyne-Stokes breathing, a decline in the patient's overall condition and their level of agitation or sedation. $^{17}$

\section{Communication of prognosis}

Regardless of the method used to develop a prognostic estimate, there is always an element of uncertainty, which may be more pronounced in conditions with a variable illness trajectory. This uncertainty is one of the barriers to initiating conversations about the future with patients; the belief being that inaccuracy will decrease trust and bad news may lead to depression and loss of hope. However, evidence suggest this is not the case if conducted in a sensitive manner. ${ }^{18}$ 
Table 3. Summary of recommendations when discussing prognosis and end of life issues - adapted from Clayton et al, Bernaki and Block, and Royal College of Physicians guidance ${ }^{18-20}$

Recommendation
Conversations about the future can be
Show empathy, care and compassion
Use clear language and deliver information at a
suitable pace tailored to each individual
Prepare for the discussion
Assess what the patient and care giver already
know and level of detail they want
Explain the uncertainty in prognostic information
and avoid giving exact time frames
Consider that caregivers' information needs may
require a separate meeting (provided the patient
consents to this, if they have mental capacity)
Ensure explanation of ongoing support and
continued care

Acknowledge and explore emotions, goals, and concerns

Encourage questions and check understanding

\section{Things to consider and examples of useful phrases}

N/A

N/A

N/A

Ensure you have adequate knowledge of the case, allocate adequate time for the discussions, find a suitable environment, and establish who should be present

'What is your understanding of your health situation and what is likely to happen?'

'Some people like to know what may happen in the future, some want to know about time, others prefer not to know too many details. What do you prefer?'

'Every person is different. I can only tell you what usually happens to people in your situation, not exactly what will happen.'

'Statistics only help us understand the big patterns of illness, not exactly what will happen for an individual with that illness.'

'Often [daughters/sons] like to ask some other questions. Is it okay if I answer your [son's/daughter's] questions? Is there anything I should not discuss?'

'We've been talking about some treatments that are not going to be effective now and that we don't recommend. But there are a lot of other things we can still do to help and support you to make sure we maximise your function and comfort.'

'If your health situation worsens, what are your most important goals?'

N/A
Like the ways in which clinicians make survival estimates, the manner of explaining prognosis can be done in a variety of ways: by providing time frames (eg weeks to months) or by providing the likelihood of being alive for certain events. No approach has been found to be superior, but a consistent finding is that exact timeframes should be avoided.

It is also important to bear in mind that estimated prognosis may change over time, as well as the patient's wish for prognostic information. In this dynamic situation, conversations involving disclosure of prognostic information can happen over several care settings and with different clinicians. Therefore, it is important to ensure adequate documentation and communication with other healthcare providers.

Guidelines (including examples of useful phrases) on how to communicate prognosis and discuss end of life issues are available. ${ }^{18,19}$ There is renewed focus with the recent Royal College of Physicians' report aiming to advise and support clinicians embarking on discussions surrounding death and dying. ${ }^{20}$ A summary of these recommendations is detailed in Table 3.

\section{References}

1 Glare PA, Sinclair CT. Palliative medicine review: prognostication. J Palliat Med 2008;11:84-103.

2 NHS. The NHS Long Term Plan. NHS, 2019. www.longtermplan.nhs. uk/wp-content/uploads/2019/01/nhs-long-term-plan.pdf [Accessed 19 January 2019].
3 National Institute of Health and Care Excellence. End of life care for adults. Quality standard [QS13]. NICE, 2017. www.nice.org.uk/ guidance/qs13 [Accessed 06 January 2019].

4 General Medical Council. Treatment and care towards the end of life: good practice in decision making. London: GMC, 2010. www.gmc-uk. org/ethical-guidance/ethical-guidance-for-doctors/treatment-andcare-towards-the-end-of-life [Accessed 06 January 2019].

5 Department of Health and Social Care. Fast track pathway tool for NHS continuing healthcare. London: Gov.uk, 2018.

6 Hospice UK. Hospice care in the UK 2016. Hospice UK, 2016 Nov. www.hospiceuk.org/docs/default-source/What-We-Offer/ publications-documents-and-files/hospice-care-in-the-uk-2016. pdf?sfvrsn $=0$ [Accessed 02 February 2019].

7 National Institute of Health and Care Excellence. Care of dying adults in the last days of life. NICE guideline [NG31]. NICE, 2015. www.nice.org.uk/guidance/ng31 [Accessed 03 February 2019].

8 The Gold Standards Framework, Royal College of General Practitioners. The Gold Standards Framework proactive identification guidance (PIG). The Gold Standards Framework, 2016. www.goldstandardsframework.org.uk/cd-content/uploads/ files/PIG/NEW \% 20PIG \% 20- \% 20 \% 20\% 2020.1.17\% 20KT \% 20 vs17.pdf [Accessed 03 February 2019].

9 White N, Kupeli N, Vickerstaff V, Stone P. How accurate is the 'surprise question' at identifying patients at the end of life? A systematic review and meta-analysis. BMC Medicine 2017:15:139.

10 Glare P, Virik K, Jones M et al. A systematic review of physicians' survival predictions in terminally ill cancer patients. BMJ 2003;327:195.

11 White N, Reid F, Harris A, Harries P, Stone P. A systematic review of predictions of survival in palliative care: how accurate are clinicians and who are the experts? PLOS one 2016:11:e0161407. 
12 Hui D, Kilgore K, Nguyen L et al. The accuracy of probabilistic versus temporal clinician prediction of survival for patients with advanced cancer: a preliminary report. Oncologist 2011;16:1642-8.

13 Gwilliam B, Keeley V, Todd C et al. Development of prognosis in palliative care study (PiPS) predictor models to improve prognostication in advanced cancer: prospective cohort study. BMJ 2011;343:d4920.

14 Downing M, Lau F, Lesperance $M$ et al. Meta-analysis of survival prediction with Palliative Performance Scale. J Palliat Care 2007;23:245-52.

15 Hui D, Dos Santos R, Chisholm G et al. Bedside clinical signs associated with impending death in patients with advanced cancer: preliminary findings of a prospective, longitudinal cohort study. Cancer 2015;121:960-7.

16 Domeisen Benedetti F, Ostgathe C, Clark J et al. International palliative care experts' view on phenomena indicating the last hours and days of life. Support Care Cancer 2013;21:1509-17.

17 White N, Harries P, Harris AJ et al. How do palliative care doctors recognise imminently dying patients? A judgement analysis. BMJ Open 2018:8:e24996.
18 Bernacki RE, Block SD, American College of Physicians High Value Care Task Force. Communication about serious illness care goals: a review and synthesis of best practices. JAMA Intern Med 2014;174:1994-2003

19 Clayton JM, Hancock KM, Butow PN et al. Clinical practice guidelines for communicating prognosis and end-of-life issues with adults in the advanced stages of a life-limiting illness, and their caregivers. Med J Aust 2007;186(12 Suppl):S77, S79, S83-108.

20 Royal College of Physicians. Talking about dying: how to begin honest conversations about what lies ahead. London, 2018. www.rcplondon. ac.uk/projects/outputs/talking-about-dying-how-begin-honestconversations-about-what-lies-ahead [Accessed 13 January 2019].

Address for correspondence: Prof Paddy Stone, University College London, Marie Curie Palliative Care Research Department, UCL Division of Psychiatry, 6th Floor, Wing A, Maple House, 149 Tottenham Court Road, London WC1E 6BT, UK.

Email: p.stone@ucl.ac.uk palliative medicine services?

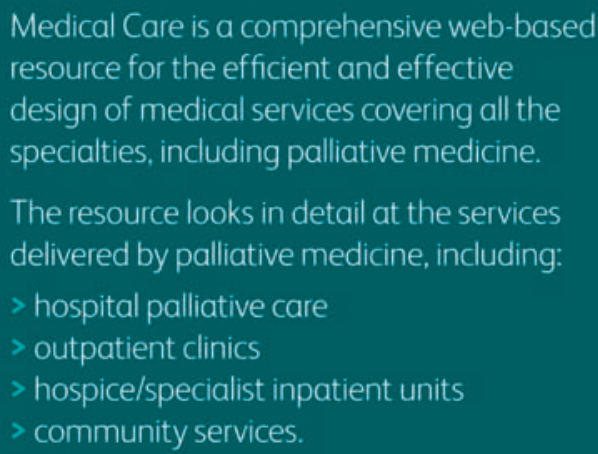
resource for the efficient and effective design of medical services covering all the specialties, including palliative medicine.

The resource looks in detail at the services delivered by palliative medicine, including:

$>$ hospital palliative care

$>$ outpatient clinics

$>$ hospice/specialist inpatient units

$>$ community services.

\section{Medical Care has been designed to help} those involved in the planning and provision of medical services get a clearer picture of the specialty services that need to be in place to provide great patient care.

\section{www.rcpmedicalcare.org.uk}

